\title{
Genetic diversity of Plasmodium falciparum populations in southeast and western Myanmar
}

Than Naing Soe ${ }^{1 \dagger}$, Yanrui Wu ${ }^{2,3 \dagger}$, Myo Win Tun ${ }^{4}$, Xin Xu' ${ }^{2}$, Yue Hu${ }^{5}$, Yonghua Ruan ${ }^{5}$, Aung Ye Naung Win ${ }^{4}$, Myat Htut Nyunt ${ }^{4}$, Nan Cho Nwe Mon ${ }^{4}$, Kay Thwe Han ${ }^{4}$, Khin Myo Aye ${ }^{4}$, James Morris ${ }^{6}$, Pincan Su Zhaoqing Yang ${ }^{2 *}$, Myat Phone Kyaw ${ }^{4,8^{*}}$ and Liwang Cui ${ }^{2,9^{*}}$

\begin{abstract}
Background: The genetic diversity of malaria parasites reflects the complexity and size of the parasite populations. This study was designed to explore the genetic diversity of Plasmodium falciparum populations collected from two southeastern areas (Shwekyin and Myawaddy bordering Thailand) and one western area (Kyauktaw bordering Bangladesh) of Myanmar.

Methods: A total of 267 blood samples collected from patients with acute P. falciparum infections during 2009 and 2010 were used for genotyping at the merozoite surface protein 1 (Msp 1), Msp2 and glutamate-rich protein (Glurp) loci.

Results: One hundred and eighty four samples were successfully genotyped at three genes. The allelic distributions of the three genes were all significantly different among three areas. MAD20 and 3D7 were the most prevalent alleles in three areas for Msp1 and Msp2, respectively. The Glurp allele with a bin size of 700-750 bp was the most prevalent both in Shwekyin and Myawaddy, whereas two alleles with bin sizes of 800-850 bp and 900-1000 bp were the most prevalent in the western site Kyauktaw. Overall, $73.91 \%$ of samples contained multiclonal infections, resulting in a mean multiplicity of infection (MOI) of 1.94. Interestingly, the MOl level presented a rising trend with the order of Myawaddy, Kyauktaw and Shwekyin, which also paralleled with the increasing frequencies of Msp1 RO33 and Msp2 FC27 200-250 bp alleles. Msp1 and Msp2 genes displayed higher levels of diversity and higher MOI rates than Glurp. PCR revealed four samples (two from Shwekyin and two from Myawaddy) with mixed infections of $P$. falciparum and P. vivax.

Conclusions: This study genotyped parasite clinical samples from two southeast regions and one western state of Myanmar at the Msp1, Msp2 and Glurp loci, which revealed high levels of genetic diversity and mixed-strain infections of $P$. falciparum populations at these sites. The results indicated that malaria transmission intensity in these regions remained high and more strengthened control efforts are needed. The genotypic data provided baseline information for monitoring the impacts of malaria elimination efforts in the region.
\end{abstract}

Keywords: Genetic diversity, Plasmodium falciparum, Multiclonal infection, Southeast and western Myanmar

\footnotetext{
* Correspondence: zhaoqingy92@hotmail.com; kyaw606@gmail.com;

luc2@psu.edu

${ }^{\dagger}$ Equal contributors

${ }^{2}$ Department of Pathogen Biology and Immunology, Kunming Medical

University, Kunming, China

${ }^{4}$ Department of Medical Research, Yangon city, Myanmar

Full list of author information is available at the end of the article
} 


\section{Background}

Malaria caused by $P$. falciparum is one of the major human infectious diseases affecting millions of people worldwide. Despite enormous control efforts over several decades, malaria still remains an important public health problem. In 2015, there were about 214 million new malaria cases and 438,000 deaths [1]. In Southeast Asia, the Greater Mekong Subregion (GMS) has been one of the most malarious areas, with immense geographical heterogeneity in endemicity and the co-existence of different Plasmodium species [2, 3]. In this region, Myanmar has the greatest malaria burden. With enhanced control efforts by the national malaria control program and support from international partners, malaria in Myanmar has been steadily declining from 1341.8 cases per 100,000 population in 2005 to 253.3 in 2014 [4]. Yet, despite significant reduction of malaria incidence, $P$. falciparum parasites still maintained a high level of genetic diversity in northeastern Myanmar [5].

The genotypic and phenotypic diversity of malaria parasites enhances their ability to counteract control measures such as therapeutic drugs. In hyperendemic areas, each individual host may harbor multiple malaria parasite strains with different genotypes, including those that confer drug resistance [6]. Sexual reproduction involving malaria parasites of different genotypes, which can occur when a mosquito feeds on an individual infected with multiple parasite strains or when the same mosquito feeds on more than one human bearing distinct parasite genotypes, favors genetic recombination and generation of higher diversity. Thus, it is expected that parasite genetic diversity tends to correlate with the transmission intensity. Likewise, many studies have shown that malaria reduction as the result of intensified control efforts is accompanied by reduced genetic diversity of the parasite populations $[7,8]$ and in some cases leads to a clonal structure of the parasite population [9]. Notably, extensive use of certain antimalarial drugs can also alter the genetic diversity as a consequence of selective sweeps. Genetic diversity, malaria demographic history and other factors in a given region may reflect the transmission intensity, effectiveness of malaria control measures, and potential emergence of resistant parasites.

In this study, we assessed the genetic diversity of $P$. falciparum parasites from three areas in southeast and western Myanmar using three polymorphic markers: merozoite surface protein 1 (Msp1), Msp2, and the glutamaterich protein (Glurp).

\section{Methods}

\section{Collection of clinical parasite samples}

Plasmodium falciparum clinical samples were collected in 2009-2010 during efficacy studies of artemisinin combination therapies conducted in three locations in
Myanmar (Shwekyin, Bago Division; Myawaddy, Kayin State; and Kyauktaw, Rakhine State; Fig. 1). Shwekyin and Myawaddy are located in southeast Myanmar, close to the Myanmar-Thailand border, whereas Kyauktaw is located in western Myanmar near the MyanmarBangladesh border. Shwekyin is $\sim 510 \mathrm{~km}$ and $\sim 220 \mathrm{~km}$ from Kyauktaw and Myawaddy, respectively. These sites were selected for the drug efficacy studies because they represent the malaria high-endemicity regions in Myanmar. In 2009, 112,653, 47,479 and 20,044 malaria cases were recorded in Rakhine State, Bago Division, and Kayin State, respectively. A total of 267 samples (56, 151, and 60 from Myawaddy, Shwekyin and

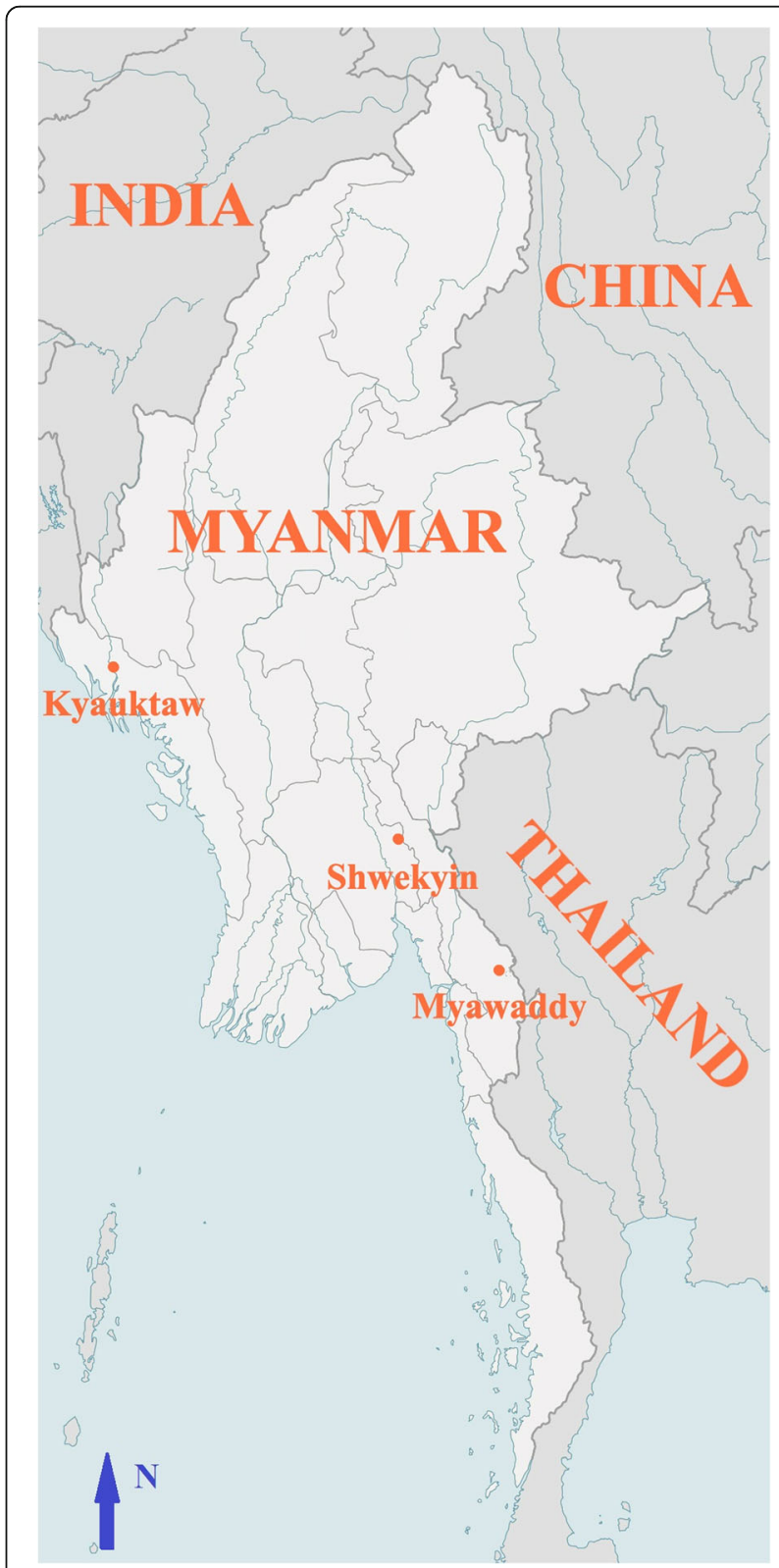

Fig. 1 Map of Myanmar showing the sample collection sites 
Kyauktaw, respectively) were obtained from patients aged 6-70 years with acute malaria (Additional file 1: Table S1). All cases were confirmed to have P. falciparum infection by microscopic examination of Giemsastained thick and thin blood smears at the local clinics. For parasite genotyping, $200 \mu \mathrm{l}$ of finger-pricked blood was spotted on $3 \mathrm{~mm}$ Whatman filter paper, dried, and stored at $4{ }^{\circ} \mathrm{C}$ until DNA extraction.

\section{Species identification and genotyping of $P$. falciparum Msp1, Msp2 and Glurp}

Parasite genomic DNA was extracted from filter papers using the QIAamp DNA micro kit (Qiagen, Hilden, Germany) following the manufacturer's instructions. Nested polymerase chain reaction (PCR) was used to identify the Plasmodium species with primers specific for $P$. falciparum, $P$. vivax, $P$. malariae, $P$. ovale and $P$. knowlesi [10-12]. The different genotypes of Msp1, Msp2, and Glurp genes were amplified by using a nested PCR method as previously described $[5,13,14]$. The PCR products were separated on $2 \%$ agarose gel and stained with ethidium bromide. The size of the PCR products was estimated based on their mobility relative to the standard DNA ladder marker (TaKaRa, Kusatsu, Japan).

\section{Estimating allele frequencies and clone numbers}

Alleles were identified based on the type and the fragment size of PCR products and assigned to different size bins. If an isolate had one allele at each of the three loci, this sample was considered to have a monoclonal infection. The multiplicity of infection (MOI) was defined as the largest number of alleles among three loci detected in the sample. This measure is conservative and it likely underestimates the number of clones present [15]. Yet, this may best reflect the level of endemicity in these areas.

\section{Statistical analysis}

The Msp1, Msp2 and Glurp allele frequencies were expressed as percentages. The proportions of alleles observed in each gene among three areas were compared using the Chi-square test. Pairwise comparison of MOI was done by Student's t-test. The correlation between MOI and percentages of gametocytemic patients was analyzed by using Spearman's correlation. The $P$ value less than 0.05 was considered statistically significant.

\section{Results}

\section{Parasite samples}

The demographic and clinical characteristics of the study populations are presented in Table 1 . Since the samples were collected from drug efficacy trials and the number of patients at each site did not reflect the level of local malaria transmission, the data could not be used for vigorous epidemiological comparisons. Yet, a significantly higher density of asexual parasites was detected from children in Myawaddy. At the time of enrollment to the efficacy studies, $21.19 \%, 10.71 \%$ and $15 \%$ patients in Shwekyin, Myawaddy and Kyauktaw carried gametocytes, respectively (Table 1). Although all patients were confirmed to have P. falciparum infections by microscopic examination, nested PCR identified four samples as $P$. falciparum and $P$. vivax mixed infections (two from each of the southeast sites). Other Plasmodium species ( $P$. malariae, P. ovale or P. knowlesi) were not detected.

\section{Variants of Msp1, Msp2 and Glurp genes}

Of the 267 samples, 184 were successfully genotyped in Msp1, Msp2 and Glurp genes. The PCR fragment sizes and allelic frequencies for Msp1, Msp2 and Glurp in three areas are shown in Table 2. The allelic distributions of Msp1, Msp2 and Glurp genes were significantly different among three areas (Table 2). The most abundant allele

Table 1 Comparison of patient profiles from three regions of Myanmar

\begin{tabular}{|c|c|c|c|c|}
\hline & $\begin{array}{l}\text { Shwekyin } \\
\text { (Southeast Myanmar) }\end{array}$ & $\begin{array}{l}\text { Myawaddy } \\
\text { (Southeast Myanmar) }\end{array}$ & $\begin{array}{l}\text { Kyauktaw } \\
\text { (Western Myanmar) }\end{array}$ & Total \\
\hline Number of patients (males \%) & $151(72.85)$ & $56(67.86)$ & $60(75)$ & $267(72.28)$ \\
\hline Age (yrs), median (range) & $23(6-66)$ & $24(6-56)$ & $20(6-56)$ & $22(6-66)$ \\
\hline $6-15$ years, $n(\%)$ & $32(21.19)$ & $19(33.93)$ & $27(45)$ & $78(29.21)$ \\
\hline$>15$ years, $n(\%)$ & $119(78.81)$ & $37(66.07)$ & $33(55)$ & $189(70.79)$ \\
\hline $\begin{array}{l}\text { Feverish patients on day } 0(\%) \\
\text { (axillary temperature } \geq 37.5^{\circ} \mathrm{C} \text { ) }\end{array}$ & 58.28 & 96.43 & 53.33 & 65.17 \\
\hline Temperature $\left({ }^{\circ} \mathrm{C}\right)$, mean (range) & $38.03(36.10-41.40)$ & $38.87(36.80-40.00)$ & $37.7(36.40-40.20)$ & $38.13(36.10-41.40)$ \\
\hline \multicolumn{5}{|c|}{ Asexual parasite density on day 0 , geometric mean (range) } \\
\hline $6-15$ years $(n=78)$ & $18,430(986-70,751)$ & $21,686(580-80,590)$ & $16,126(645-63,620)$ & $18,425(580-80,590)$ \\
\hline$>15$ years $(n=189)$ & $15,397(504-93,310)$ & $8887(681-83,894)$ & $13,494(674-56,369)$ & $13,790(504-93,310)$ \\
\hline Gametocytemic patients on day 0 (\%) & 21.19 & 10.71 & 15.00 & 17.23 \\
\hline
\end{tabular}


Table 2 Allele types and frequencies of Msp1, Msp2 and Glurp genes

\begin{tabular}{|c|c|c|c|c|c|c|c|}
\hline \multirow[t]{2}{*}{ Gene (total allele numbers) } & \multirow[t]{2}{*}{ Type } & \multirow[t]{2}{*}{ Size (bp) } & \multirow{2}{*}{$\begin{array}{l}\text { Shwekyin } \\
\text { (Southeast Myanmar) } \\
n(\%)\end{array}$} & \multirow{2}{*}{$\begin{array}{l}\text { Myawaddy } \\
\text { (Southeast Myanmar) } \\
n(\%)\end{array}$} & \multirow{2}{*}{$\begin{array}{l}\text { Kyauktaw } \\
\text { (Western Myanmar) } \\
n(\%)\end{array}$} & \multirow[t]{2}{*}{ Total } & \multirow[t]{2}{*}{$P$-value } \\
\hline & & & & & & & \\
\hline \multirow[t]{5}{*}{ Msp1 (311) } & \multirow[t]{2}{*}{ K1 } & $120-200$ & $34(19.54)$ & $25(34.73)$ & $12(18.46)$ & $71(22.83)$ & \multirow{5}{*}{$\begin{array}{l}X^{2}=21.03, d f=8 \\
P=0.0071\end{array}$} \\
\hline & & $250-300$ & $0(0)$ & $1(1.39)$ & $3(4.62)$ & $4(1.29)$ & \\
\hline & \multirow[t]{2}{*}{ MAD20 } & $120-150$ & $27(15.52)$ & $12(16.67)$ & $8(12.31)$ & $47(15.11)$ & \\
\hline & & $180-300$ & $56(32.18)$ & $23(31.94)$ & $26(40.00)$ & $105(33.76)$ & \\
\hline & $\mathrm{RO} 33$ & $150-200$ & $57(32.76)$ & $11(15.28)$ & $16(24.62)$ & $84(27.01)$ & \\
\hline \multirow[t]{6}{*}{ Msp2 (291) } & \multirow[t]{3}{*}{ 3D7 } & $350-400$ & $14(8.75)$ & $19(24.68)$ & $1(1.85)$ & $34(11.68)$ & \multirow{6}{*}{$\begin{array}{l}X^{2}=35.78, d f=10 \\
P<0.0001\end{array}$} \\
\hline & & $450-550$ & $80(50.00)$ & $45(58.44)$ & $30(55.56)$ & $155(53.26)$ & \\
\hline & & $600-700$ & $9(5.63)$ & $0(0)$ & $3(5.56)$ & $12(4.12)$ & \\
\hline & \multirow[t]{3}{*}{ FC27 } & $200-250$ & $14(8.75)$ & $0(0)$ & $1(1.85)$ & $15(5.15)$ & \\
\hline & & $280-350$ & $41(25.63)$ & $13(16.88)$ & $18(33.33)$ & $72(24.74)$ & \\
\hline & & $400-500$ & $2(1.25)$ & $0(0)$ & $1(1.85)$ & $3(1.03)$ & \\
\hline \multirow[t]{4}{*}{ Glurp (208) } & & $500-600$ & $10(9.60)$ & $1(1.85)$ & $0(0)$ & $11(5.29)$ & \multirow{4}{*}{$\begin{array}{l}X^{2}=20.57, d f=6 \\
P=0.0022\end{array}$} \\
\hline & & $700-750$ & $48(46.20)$ & $23(42.6)$ & $12(24.0)$ & $83(39.9 \%)$ & \\
\hline & & $800-850$ & $28(26.90)$ & $20(37.0)$ & $19(38.0)$ & $67(32.21 \%)$ & \\
\hline & & $900-1000$ & $18(17.30)$ & $10(18.5)$ & $19(38.0)$ & $47(22.6 \%)$ & \\
\hline
\end{tabular}

types of Msp1 and Msp2 of all three areas were MAD20 and 3D7, respectively. Shwekyin and Myawaddy both shared the same dominant Glurp allele of 700-750 bp, but the most prevalent Glurp alleles in Kyauktaw were 800850 bp and $900-1000$ bp. Compared to Glurp, Msp1 and Msp2 displayed higher genetic diversity in all three areas (Additional file 2: Table S2).

\section{Multiclonal infections}

Of the 184 samples successfully genotyped for all three genes, only $26.09 \%$ samples were mono- allelic at each of the three genes (Table 3). Analysis of Msp1 and Msp2 revealed $52.72 \%$ and $54.35 \%$ samples harboring multiclonal infections, respectively, whereas analysis of Glurp identified $13.04 \%$ multiclonal infections. When the genotyping results from three loci were combined, $73.91 \%$ of the samples were multiclonal infections, giving a mean
MOI of 1.94. Among the three areas, the levels of multiclonal infections ranged from 64 to $80.21 \%$, and the MOI ranged from 1.70 to 2.05 . The lowest MOI was found in Myawaddy, which was significantly lower than that in Shwekyin $\left(t\right.$-test: $\left.t_{(144)}=3.096, P=0.002\right)$. In addition, the MOI did not show significant correlation with the proportion of gametocytemic patients in each site (Spearman correlation: $r_{(184)}=0.1, P=0.2$ ).

\section{Discussion}

The genetic diversity of $P$. falciparum parasites impacts malaria transmission and malaria control strategies. Therefore, it is important to resolve the genetic population structure of $P$. falciparum parasites in epidemic areas. Here we compared the genetic diversity of $P$. falciparum populations in two southeast regions and one western state of Myanmar using three polymorphic antigen

Table 3 Multiclonal infections in Shwekyin, Myawaddy and Kyauktaw of Myanmar

\begin{tabular}{|c|c|c|c|c|c|c|c|c|c|c|c|}
\hline \multirow{3}{*}{ Genes $^{a}$} & \multicolumn{10}{|c|}{ Number of alleles } & \multirow{3}{*}{ Total $(n=184)$} \\
\hline & \multicolumn{4}{|c|}{$\begin{array}{l}\text { Shwekyin } \\
\text { (Southeast Myanmar, } n=96 \text { ) }\end{array}$} & \multicolumn{3}{|c|}{$\begin{array}{l}\text { Myawaddy } \\
\text { (Southeast Myanmar, } n=50 \text { ) }\end{array}$} & \multicolumn{3}{|c|}{$\begin{array}{l}\text { Kyauktaw } \\
\text { (Western Myanmar, } n=38)\end{array}$} & \\
\hline & 2 & 3 & 4 & Total & 2 & 3 & Total & 2 & 3 & Total & \\
\hline Mspl & 37 & 19 & 1 & $57(59.38 \%)$ & 20 & 1 & $21(42.00 \%)$ & 11 & 8 & 19 (50.00\%) & $97(52.72 \%)$ \\
\hline Msp2 & 56 & 4 & 0 & $60(62.50 \%)$ & 23 & 2 & $25(50.00 \%)$ & 14 & 1 & 15 (39.47\%) & $100(54.35 \%)$ \\
\hline Glurp & 8 & 0 & 0 & $8(8.33 \%)$ & 4 & 0 & $4(8.00 \%)$ & 12 & 0 & $12(31.58 \%)$ & $24(13.04 \%)$ \\
\hline Combined & 54 & 22 & 1 & 77 (80.21\%) & 29 & 3 & 32 (64.00\%) & 18 & 9 & 27 (71.05\%) & 136 (73.91\%) \\
\hline MOI (Mean \pm SD) & \multicolumn{4}{|c|}{$2.05 \pm 0.69$} & \multicolumn{3}{|c|}{$1.70 \pm 0.58^{b}$} & \multicolumn{2}{|c|}{$1.95 \pm 0.73$} & $1.94 \pm 0.68$ & \\
\hline
\end{tabular}

${ }^{a}$ Number (\%) of mixed strain infections identified based on one marker (Msp1, Msp2 or Glurp) or three markers together (combined)

${ }^{\mathrm{b}} \mathrm{MOI}$ is significantly different between Myawaddy and Shwekyin $\left(t_{(144)}=3.096, P=0.002\right)$ 
markers. Consistent with earlier findings, genotyping the two Msp markers $M s p 1$ and Msp2 identified significantly higher numbers of allele variants than genotyping Glurp [5, 17]. For Msp1, the MAD20 type was more prevalent than the RO33 and $\mathrm{K} 1$ alleles, as reported in other areas of the GMS including southwestern China [16], northeastern Myanmar [5] and the Thai-Myanmar border [17]. It was noteworthy that the frequency of the RO33 allele in the present study ranged from 15.28 to $32.76 \%$, which is distinct from the rare presence of this type in parasites from the central Myanmar [18]. For $M s p 2$, the 3D7 type was more abundant than the FC27 type, which was similar to what has been reported from the Thai-Myanmar border [17], but different from results in the northeastern Myanmar [5] and Laos [19]. Interestingly, all three sites shared the same most prevalent $M s p 2$ allele (3D7 type, allele size $450-550 \mathrm{bp}$ ). For Glurp, Shwekyin and Myawaddy both had the 700-750 bp allele as the most frequent, whereas the $800-850 \mathrm{bp}$ and 900-1000 bp alleles were the most common ones from Kyauktaw. The genetic similarities of the analyzed $P$. falciparum may reflect the geographical proximity of the study areas and possible population mixing from neighboring areas of the GMS. For example, the genetic diversity of parasites from the southeast site Myawaddy described in this study was similar to that from the Thai-Myanmar border [17]. Overall, the three polymorphic markers revealed high levels of genetic diversity of parasite populations from the three areas. This suggests that despite the malaria control efforts, the parasite's effective population remained large in these historically high-endemicity areas. Significant sharing of certain alleles may be attributed to extensive human migration along the border areas, which serves as a vehicle for introducing and spreading of parasites between sites [2].

The level of MOI usually reflects the degree of transmission intensity, although the association is not linear $[7,20]$. Genotyping the three polymorphic markers in this study revealed that at least $73.91 \%$ of the analyzed samples were mixed infections. The largest number of alleles detected from a single isolate was 4, 3 and 2 for Msp1, Msp2 and Glurp, respectively. Such a high level of mixed infections indicates that transmission intensity was still high in these regions. Moreover, the trend for increased MOI to parallel the increased frequencies of the Msp1 RO33 and the Msp2 FC27 200-250 bp alleles suggested that these allelic types may be used as molecular markers for malaria prevalence or burden assessment in the region. Whereas this study and our earlier work in northeastern Myanmar using the same antigenic markers identified similarly high levels of genetic diversity of the parasites in spite of recent drastic reduction in malaria cases, the northeastern region had significantly lower MOI [4]. As the genetic diversity is expected to decrease in the face of malaria elimination, the information provided herein may serve as the baseline data for continued epidemiological surveillance in these endemic regions.

It is interesting to note that although this study was not designed to detect the prevalence of all malaria parasites, PCR analysis did identify four cases of mixed $P$. falciparum/ P. vivax infections. These four misdiagnosed samples were not in the same area. Misdiagnosis of the mixed infections is most likely due to lower parasitemia normally associated with $P$. vivax infections. Given that the missed $P$. vivax co-infections would preclude treatment with primaquine for anti-relapse therapy, it is likely that some of these patients would experience $P$. vivax relapses. Therefore, more detailed epidemiological studies involving all human parasites are needed to clarify the prevalence, dynamics and genetics of the parasites in the endemic regions of Myanmar.

\section{Conclusion}

This study described the genetic diversity of $P$. falciparum from two southeast regions and one western state of Myanmar during 2009-2010. Successful genotyping of 184 clinical samples at Msp1, Msp2 and Glurp revealed high levels of genetic diversity and MOI, indicating that $P$. falciparum transmission remained relatively intense in these regions. These results can serve as the baseline information to monitor the effectiveness of the malaria elimination efforts. We can compare the MOI with future's data, to assay the effect of the prevention measures.

\section{Additional files}

Additional file 1: Table S1. The information of all samples. (XLS $376 \mathrm{~kb}$ )

Additional file 2: Table S2. Allele sizes and types of Msp1, Msp2 and Glurp genes. (XLS $83 \mathrm{~kb}$ )

\section{Abbreviations \\ Glurp: glutamate-rich protein; GMS: Greater Mekong Subregion; MOl: multiplicity of infection; Msp 1: merozoite surface protein 1; Msp2: merozoite surface protein 2}

\section{Acknowledgements}

We thank the staff at the clinics and patients for participation in this study. We also thank Miss Yao Bai and Mr. Weilin Zeng for assisting data analysis.

\section{Funding}

This study was funded by the National Natural Science Foundation of China (grants U1202226 and 31,260,508); a Talent Introduction Project of Yunnan Province (grant 2013HA026); the National Institutes of Health, USA (grant U19AI089672); the Yunnan Province Research Foundation for Basic Research, China (2014FB005); the Doctor Starting Foundation from Basic Medical Sciences of Kunming Medical University (\#1) and the WHO (Ref. No.SE/09/214744; SE.10.11500. MMI. MPRO03. MMK, INV.ERS71780-30409).

Availability of data and materials

All relevant data are within the paper.

Authors' contributions

ZY, MPK and LC conceived and designed the study. TNS, YW, XX, YH, PS and YR performed the genotyping experiments. TNS, YW and JM did the analysis 
and drafted the manuscript. MWT, AYNW, MHN, NCNM, KTH and KMA collected the parasite samples. TNS, YW, ZY, MPK and LC revised the manuscript. All authors read and approved the final manuscript.

\section{Ethics approval and consent to participate}

Ethical approval for the study was given by The Institutional Review Board of The Department of Medical Research, Myanmar. Written informed consent was gathered from the participants or their guardians prior to enrolment. The Institutional Review Board of The Department of Medical Research, Myanmar approved the subject protocol in advance of its completion. Written informed consent was gathered from the participants or their guardians prior to enrollment.

\section{Consent for publication}

Not applicable.

\section{Competing interests}

The authors declare that they have no competing interests.

\section{Publisher's Note}

Springer Nature remains neutral with regard to jurisdictional claims in published maps and institutional affiliations.

\section{Author details \\ 'Department of Public Health, Ministry of Health and Sports, Nay Pyi Taw, Myanmar. ${ }^{2}$ Department of Pathogen Biology and Immunology, Kunming Medical University, Kunming, China. ${ }^{3}$ Department of Cell Biology \& Genetics, Kunming Medical University, Kunming, China. ${ }^{4}$ Department of Medical Research, Yangon city, Myanmar. ${ }^{5}$ Department of Pathology, Kunming Medical University, Kunming, China. ${ }^{6}$ Department of Genetics and Biochemistry, Eukaryotic Pathogens Innovation Center, Clemson University, Clemson, SC, USA. ${ }^{7}$ Transfusion Medicine Research Department, Yunnan Kunming Blood Center, Kunming, China. ${ }^{8}$ Myanmar Medical Association, Yangon, Myanmar. ${ }^{9}$ Department of Entomology, Pennsylvania State University, University Park city, PA 16802, USA.}

Received: 21 December 2016 Accepted: 19 June 2017

Published online: 04 July 2017

\section{References}

1. WHO. World malaria report; 2015. p. 2015.

2. Cui L, Yan G, Sattabongkot J, Chen B, Cao Y, Fan Q, et al. Challenges and prospects for malaria elimination in the greater Mekong Subregion. Acta Trop. 2012:121(3):240-5.

3. Cui L, Yan G, Sattabongkot J, Cao Y, Chen B, Chen X, et al. Malaria in the greater Mekong Subregion: heterogeneity and complexity. Acta Trop. 2012;121(3):227-39.

4. Mu TT, Sein AA, Kyi TT, Min M, Aung NM, Anstey NM, et al. Malaria incidence in Myanmar 2005-2014: steady but fragile progress towards elimination. Malar J. 2016;15(503):1-9.

5. Yuan L, Zhao H, Wu L, Li X, Parker D, Xu S, et al. Plasmodium falciparum populations from northeastern Myanmar display high levels of genetic diversity at multiple antigenic loci. Acta Trop. 2012;125(1):53-9.

6. Robinson T, Campino SG, Auburn S, Assefa SA, Polley SD, Manske M, et al. Drug-resistant genotypes and multi-clonality in Plasmodium falciparum analysed by direct genome sequencing from peripheral blood of malaria patients. PLoS One. 2011;6(8):e23204.

7. Hoffmann EH, da Silveira LA, Tonhosolo R, Pereira FJ, Ribeiro WL, Tonon AP, et al. Geographical patterns of allelic diversity in the Plasmodium falciparum malaria-vaccine candidate, merozoite surface protein-2. Ann Trop Med Parasitol. 2001:95(2):117-32.

8. Daniels R, Chang HH, Sene PD, Park DC, Neafsey DE, Schaffner SF, et al. Genetic surveillance detects both clonal and epidemic transmission of malaria following enhanced intervention in Senegal. PLoS One. 2013;8(4):e60780.

9. Putaporntip C, Miao J, Kuamsab N, Sattabongkot J, Sirichaisinthop J, Jongwutiwes $\mathrm{S}$, et al. The Plasmodium vivax merozoite surface protein 3 beta sequence reveals contrasting parasite populations in southern and northwestern Thailand. PLoS Negl Trop Dis. 2014;8(11):e3336.

10. Johnston SP, Pieniazek NJ, Xayavong MV, Slemenda SB, Wilkins PP, da Silva AJ. $P C R$ as a confirmatory technique for laboratory diagnosis of malaria. J Clin Microbiol. 2006;44(3):1087-9.
11. Buppan P, Putaporntip C, Pattanawong U, Seethamchai S, Jongwutiwes S. Comparative detection of Plasmodium vivax and Plasmodium falciparum DNA in saliva and urine samples from symptomatic malaria patients in a low endemic area. Malar J. 2010;9:72.

12. Yan J, Li N, Wei X, Li P, Zhao Z, Wang L, et al. Performance of two rapid diagnostic tests for malaria diagnosis at the China-Myanmar border area. Malar J. 2013;12:73.

13. Kaneko O, Kimura M, Kawamoto F, Ferreira MU, Tanabe K. Plasmodium falciparum: allelic variation in the merozoite surface protein 1 gene in wild isolates from southern Vietnam. Exp Parasitol. 1997;86(1):45-57.

14. Viriyakosol S, Siripoon N, Petcharapirat C, Petcharapirat P, Jarra W, Thaithong S, et al. Genotyping of Plasmodium falciparum isolates by the polymerase chain reaction and potential uses in epidemiological studies. Bull World Health Organ. 1995;73(1):85-95

15. Hill WG, Babiker HA. Estimation of numbers of malaria clones in blood samples. Proc Biol Sci. 1995;262(1365):249-57.

16. Zhu X, Zhou L, Liu Q, Gao X. Genotype and sequence analysis of merozoite surface protein 1 of Plasmodium falciparum isolates in Yunnan province. Zhongguo Ji Sheng Chong Xue Yu Ji Sheng Chong Bing Za Zhi. 1999:17(3):155-8. (In Chinese)

17. Congpuong K, Sukaram R, Prompan Y, Dornae A. Genetic diversity of the msp-1, msp-2, and glurp genes of Plasmodium falciparum isolates along the Thai-Myanmar borders. Asian Pac J Trop Biomed. 2014;4(8):598-602.

18. Kang JM, Moon SU, Kim JY, Cho SH, Lin K, Sohn WM, et al. Genetic polymorphism of merozoite surface protein-1 and merozoite surface protein-2 in Plasmodium falciparum field isolates from Myanmar. Malar J. 2010;9:131.

19. Khaminsou N, Kritpetcharat O, Daduang J, Charerntanyarak L, Kritpetcharat P. Genetic analysis of the merozoite surface protein-1 block 2 allelic types in Plasmodium falciparum clinical isolates from Lao PDR. Malar J. 2011;10:371.

20. Paul RE, Hackford I, Brockman A, Muller-Graf C, Price R, Luxemburger C, et al. Transmission intensity and Plasmodium falciparum diversity on the northwestern border of Thailand. Am J Trop Med Hyg. 1998:58(2):195-203.

\section{Submit your next manuscript to BioMed Central and we will help you at every step:}

- We accept pre-submission inquiries

- Our selector tool helps you to find the most relevant journal

- We provide round the clock customer support

- Convenient online submission

- Thorough peer review

- Inclusion in PubMed and all major indexing services

- Maximum visibility for your research

Submit your manuscript at www.biomedcentral.com/submit
Biomed Central 